\title{
A EDUCAÇÃo PARA O CONSUMO E O ENSINO dE CIÊNCIAS NO BRASIL. INTERDISCIPLINARIDADE, CIDADANIA E TRANSVERSALIDADE
}

\author{
THE CONSUMERING EDUCATION AND THE TEACHING OF \\ SCIENCE IN BRAZIL. INTERDISCIPLINARITY, CITIZENSHIP \\ AND TRANSVERSAL THEME
}

\author{
Edson Cardia* \\ Fernando Bastos***
}

\section{Resumo}

O presente ensaio demonstra a possibilidade de se integrar os preceitos do Código Brasileiro de Defesa do Consumidor (CDC) ao Ensino de Ciências (Biologia, Física, Química) e Matemática, oferecendo exemplos do dia-a-dia pelos quais os professores poderão implementar, em suas disciplinas, os objetivos de cidadania vertentes na educação de nossos jovens.

Palavras chave: Educação; consumismo; Código Brasileiro de Defesa do Consumidor; ensino de ciências.

\begin{abstract}
This paper shows the possibility of integrating -- as a transversal theme -- the precepts of the Brazilian Consumer Defense Code (CDC -- Código Brasileiro de Defesa do Consumidor) to the teaching of Science (Biology, Physics, Chemistry) and of Mathematics, offering examples from daily life through which teachers will be able to include in the practice of their subjects the purposes of citizenship of our youth education.
\end{abstract}

Key words: Education; Consumering; Brazilian Consumer Defense Code; teaching of Science.

* Mestre e Doutorando junto ao Programa de Pós-Graduação em Educação para a Ciência da Universidade stadual Paulista, Unesp, Faculdade de Ciências, Campus de Bauru, Grupo de Pesquisa em Educação para a Ciência, PGFC, Unesp, Bauru. E-mail: cardia@fc.unesp.br

** Professor Assistente-Doutor do Departamento de Educação e Docente do Programa de Pós-Graduação em Educação para a Ciência da Universidade Estadual Paulista, Unesp, Faculdade de Ciências, Campus de Bauru, Grupo de Pesquisa em Educação para a Ciência, PGFC, Unesp, Bauru. 


\section{INTRODUÇÃO}

Não é inviável estabelecer uma relação direta entre um ou vários instrumentos jurídicos colocados à disposição da população e o ensino de Ciências. No caso apresentado neste trabalho, que trata sobre a educação para o consumo fixando o aluno no pólo consumidor, ressaltando sua condição de pessoa e cidadão, a resposta para uma indagação neste sentido é afirmativa e permite uma rica demonstração de viabilidade.

$\mathrm{O}$ artigo dedica-se à tarefa de expor objetivos adicionais ao espírito do Código de Defesa do Consumidor (CDC) estendendo o foco dos professores de Ciências ao ambiente jurídico da referida relação consumerista, revelando que poderão implementar um amplo trabalho harmonizando o trinômio Ciência, Tecnologia e Sociedade, sempre sob os contornos ditados pela busca do ideal de cidadania.

\section{Alguns excertos do texto DO CDC ${ }^{1}$ DENTRE AQUELES APLICÁVEIS AO TEMA}

\section{TÍTULO I}

\section{Dos Direitos do Consumidor}

\section{CAPÍTULO I}

\section{Disposições Gerais}

Art. $2^{\circ}$ Consumidor é toda pessoa física ou jurídica que adquire ou utiliza produto ou serviço como destinatário final.

Parágrafo único. Equipara-se a consumidor a coletividade de pessoas, ainda que indetermináveis, que haja intervindo nas relações de consumo.

Art. $3^{\circ}$ Fornecedor é toda pessoa física ou jurídica, pública ou privada, nacional ou estrangeira, bem como os entes despersonalizados, que desenvolvem atividade de produção, montagem, criação, construção, transformação, importação, exportação, distribuição ou comercialização de produtos ou prestação de serviços.

$-1^{\circ}$ Produto é qualquer bem, móvel ou imóvel, material ou imaterial.

$-2^{\circ}$ Serviço é qualquer atividade fornecida no mercado de consumo, mediante remuneração, inclusive as de natureza bancária, financeira, de crédito e securitária, salvo as decorrentes das relações de caráter trabalhista.

\section{CAPÍTULO II}

\section{Da Política Nacional de Relações de Consumo}

Art. $4^{\circ}$ A Política Nacional de Relações de Consumo tem por objetivo o atendimento das necessidades dos consumidores, o respeito a sua dignidade, saúde e segurança, a proteção de seus interesses econômicos, a melhoria da sua qualidade de vida, bem como a transferência e harmonia das relações de consumo, atendidos os seguintes princípios:

$\cdots$

IV - educação e informação de fornecedores e consumidores, quanto aos seus direitos e deveres, com vistas à melhoria do mercado de consumo;

1 Grinover et alii, CDC Comentado, 2000. 


\section{CAPÍTULO III}

Dos Direitos Básicos do Consumidor

Art. $6^{\circ}$ São direitos básicos do consumidor:

$\cdots$

II - a educação e divulgação sobre o consumo adequado dos produtos e serviços, asseguradas a liberdade de escolha e a igualdade nas contratações;

III - a informação adequada e clara sobre os diferentes produtos e serviços, com especificação correta de quantidade, características, composição, qualidade e preço, bem como sobre os riscos que apresentem;

\section{O tema no ensino de Ciências e Matemática}

Retira-se dos Parâmetros Curriculares Nacionais (PCN) para o ensino médio, naquilo que trata do ensino das ciências da natureza, que os objetivos dessa fase instrucional, em cada uma das áreas do conhecimento relacionadas e portanto de forma combinada, devem ser desenvolvidos conhecimentos práticos, contextualizados, que respondam às necessidades da vida contemporânea, e o desenvolvimento de conhecimentos mais amplos e abstratos que correspondam a uma cultura geral e a uma visão de mundo (Brasil, PCN, 1999, p. 16).

Reformulados em 2002, os PCN-Mais reafirmam o aspecto da transversalidade, dispondo que as três áreas - Ciências da Natureza e Matemática, Ciências Humanas, Linguagens e Códigos - organizam e interligam isciplinas, mas não as diluem nem as eliminam (ob cit. p. 8).
Acrescenta o documento original que tais objetivos são particularmente verdadeiros nas áreas cogitadas, tendo em vista que a crescente valorização do conhecimento e da capacidade de inovar torna os alunos cidadãos aptos para um aprendizado contínuo que exige uma formação geral preferencialmente a um treinamento específico.

Com efeito, a obra no Volume 10 enuncia os temas propostos: Ética, Meio Ambiente, Pluralidade Cultural, Saúde, Orientação Sexual, Trabalho e Consumo, razão pela qual recebeu o título geral de Temas Transversais, indicando a metodologia proposta para sua inclusão no currículo e seu tratamento didático.

A visão de mundo imaginada para o ensino médio pressupõe uma articulação interdisciplinar e o desenvolvimento do espírito crítico nos alunos, fatos que transpassam para a capacidade intelectiva correspondente ao juízo avaliativo de tudo quanto é colocado no meio social a partir das novas descobertas científicas e do progresso tecnológico atuais.

Nesse campo não é viável estabelecer fronteiras disciplinares, ocorrendo que as atividades regulatórias, hoje objeto de ampla discussão em vários segmentos, como por exemplo no caso específico dos organismos geneticamente modificados, impõe um afinado senso crítico para que a população possa discernir entre os vários discursos das partes envolvidas, estabelecendo conclusões amadurecidas sobre o que melhor convém à sociedade diante dos avanços da ciência e da tecnologia. 
Devem igualmente conhecer quais os recursos colocados à disposição da população consumidora que viabilizam a proteção que lhes é necessária em face do poder econômico e seus possíveis interesses não desejados.

Segundo Filomeno (1999), a política geral de proteção prevista do Código Brasileiro do Consumidor consiste define:

basicamente há preocupação fundamental de se proteger o consumidor quanto a prejuízos à sua saúde e segurança, fomentar e proteger os interesses econômicos dos consumidores, fornecer aos consumidores informações adequadas para capacitá-los a fazer escolhas acertadas de acordo com suas necessidadese desejos individuais, educar o consumidor,criar possibilidades de real ressarcimento ao consumidor, garantir a liberdade para formar grupos de consumidores...

É possível estabelecer um paralelo entre a Educação para o Consumo e a Educação Ambiental, por ter sido esta também incipiente até alguns anos passados e experimentou um grande avanço atingindo o patamar de importância que atualmente se observa..

A correlação mencionada pode ser verificada pela simetria de objetivos conforme se pode retirar do excerto:

La problemática ambiental se ha acelerado y agudizado en las últimas décadas, en un contexto en el que la globalización económica impone nuevas pautas para la producción y consumo de recursos. En dicho contexto la educación es una vía útil y necesaria para potenciar al máximo la formación y capacitación ambiental en distintos ámbitos de la sociedad, desde quienes tienen en sus manos la toma de decisiones importantes, hasta los niveles ciudadanos, en los que la actuación diaria incide en forma directas obre el médio. (Frers, 2005).

A percepção acurada dos meandros ainda não de todo elucidados pela Biologia em que pese a decifração genética e a organização molecular da vida, nos dizeres do mesmo PCN (p. 24), não é um luxo acadêmico mas um pressuposto para a compreensão mínima dos mecanismos de hereditariedade e mesmo da biotecnologia contemporânea .

A oportunização de conjugar a atividade dos meios regulatórios e protetivos, aplicados individual ou coletivamente, com os conteúdos disciplinares contribui para a formação cidadã dos estudantes de ensino médio e fundamental pelo exame crítico dos resultados da ciência, da tecnologia, tomada no sentido da instrumentalização disponível àquela interagindo todos estes fatores com os anseios sociais.

Nesse sentido é possível afirmar que no se puede transmitir conocimientos como si fuesen porciones (Driver, 1989).

Um alerta sobre a questão da fragmentação dos saberes foi estabelecido por Zabala (2002, p.15) ao analisar as diferenças existentes entre as finalidades da ciência e do ensino, prelecionando que o reflexo na escola, dessa diversificação é a seleção ou a distribuição dos conteúdos escolares a partir de parâmetros basicamente disciplinares.

Nessa vertente, se forem questionados os modelos tradicionais de ensino, 
obter-se-á como resultado desta reflexão a concretização de modelos didáticos globalizados sem descurar que não se estabelece nesse questionamento, nenhuma metodologia concreta, apenas se coloca em debate a organização tradicional dos conteúdos (multidiplinaridade).

Resumidamente, propõe-se a intervenção na realidade, alterando-se os eixos que organizam os conteúdos, buscando uma aprendizagem significativa tão intensa quanto possível.

Para Sanmarti (1999, p.54), focando o tema no ensino de ciências:

El reto actual de la clase de Ciencias no es tanto transmitir información como enseñar a utilizarla, a establecer relaciones entre informaciones aparentemente dispares $y$, muy especialmente, a comunicar nuestras ideas e interpretar las expresadas por los demás. Este artículo sostiene la idea de que enseñar a hablar y escribir ciencia ha de ser uno de los objetivos prioritarios de las clases, para que muchas más personas accedan a esta forma de conocimiento.

Como exemplo, relembrando o empenho da IOCU (International Organization of Consumers Unions, atualmente denominada de $\mathrm{Cl}$ - Consumers International), órgão assentado na ONU ( Organização das Nações Unidas) vimos que dentre as sugestões para a elaboração de legislações de defesa dos consumidores, insere-se a proteção dos consumidores frente aos riscos para sua saúde e segurança, objetivo que está presente em nosso $C D C$, no título ligado à política nacional de relações de consumo (art. $4^{\circ}$ ), e tem por objetivo o atendimento das necessidades dos consumidores, o respeito a sua dignidade, saúde e segurança, a proteção de seus interesses econômicos, a melhoria da sua qualidade de vida.

Os componentes da Educação para o Consumo, seriam:

a. Fundamentos do consumo.

b. Conscientização: tem natureza conceitual. Cabe ao professor mostrar as formas - como - as ações individuais e em grupo podem influenciar na relação entre os fornecedores de serviços e produtos e os consumidores, tendo em vista que as atitudes afetam as regras e o conhecimento destas pode ajudar a orientar as condutas das pessoas - porquê -

c. A procura e análise de problemas, oportunizando aos alunos a aprendizagem sobre investigar e avaliar quesotes relativas ao consumo.

d. Desenvolvimento da capacidade de agir, dotando os alunos de habilidades suficientes para se tornarem participantes na solução de problemas atuais e futuro, neste caso prevenindo-os).

Para que os objetivos delineados para a educação sobre o consumo sejam alcançados, a reforma deve se originar dos próprios educadores e não do exterior (Morin, 2002, p. 35). passando de uma concepção fragmentária para uma concepção unitária do conhecimento.

Edgar Morin (Ibidem) adverte, entretanto que a ação que a interdisciplinaridade pode exercer é de uma abrangência muito pequena: 
Sabemos cada vez mais que as disciplinas se fecham e não comungam umas com as outras. Os fenômenos são cada vez mais fragmentados, e não consegue conceber-se sua unidade. É por isso que se diz cada vez mais: 'Façamos a interdisciplinaridade.' Mas a interdisciplinaridade controla tanto as disciplinas quanto a ONU controla as nações. Cada disciplina pretende fazer reconhecer a sua soberania territorial, e, à custa de algumas magras trocas, as fronteiras confirmam-se em vez de desmoronarem.

Ultrapassando este conteúdo programático, o código inseriu no artigo $6^{\circ}$. os direitos básicos do consumidor, iniciando-os com a proteção da vida, saúde e segurança contra os riscos provocados por práticas no fornecimento de produtos e serviços considerados perigosos ou nocivos.

A interdisplinaridade encontra aqui o seu importante papel tendo em vista ser de sua essência a formação de estudantes dotados de uma visão global de mundo e capazes de articular, religar, contextualizar, situar-se num contexto e, se possível, globalizar, reunir conhecimentos adquiridos (Morin, 2002, p. 29).

De outro lado, o planejamento integrado e a adoção da transversalidade com parâmetros sócio-economicos para a elaboração das políticas de desenvolvimento serão essenciais para evitar conflitos de consumo e ações governamentais contraditórias.

O noticiário em geral mostra que no cotidiano não tem sido raro que os consumidores e o público em geral, através da mídia, deparem-se com verdadeiros atentados aos hábitos de higiene essenciais como no caso do controle da bacté- ria Salmonela (Salmonella typhimurium e Salmonella enteritidis), considerada uma das principais causas de infecções alimentares.

No propósito assegurado pelo próprio $\mathrm{CDC}$, integrando como direito básico a educação e divulgação sobre o consumo adequado dos produtos e serviços, poderá estar bem delineado o importante papel do professor de Ciências ou Biologia, prelecionando sobre este aspecto da segurança alimentar, integrando a norma jurídica colocada à disposição do cidadão e um conteúdo específico, preparando, bem, os seus alunos.

Poderão ser debatidos, ainda em caráter de mero exemplo, a origem do microorganismo encontrado principalmente em alimentos de origem animal, como ovos, leite e carnes, bem como os riscos à saúde causados por ela, os vários serotipos e espécies, responsáveis por quadros clínicos bem diferentes, alguns dados epidemiológicos ilustrativos evidenciando-se que no Brasil, nos últimos cinco anos, foram registrados 749 surtos de infecção por salmonela dos quais 277 causados especificamente pelo consumo de ovos ou maionese caseira contaminados, que se constituem assim nos principais meios de veiculação da bactéria ${ }^{2}$.

Na mesma linha, poderão os professores ilustrar aos seus alunos a vigência do primeiro regulamento nacional de boas práticas para serviços de alimentação contendo regras de orientação para co-

\footnotetext{
2 Fonte: Agência Brasil, Dezembro 2004
} 
merciantes a procederem de maneira adequada e segura a manipulação, preparo, acondicionamento, armazenamento, transporte e exposição à venda dos alimentos.

Tudo objetivando, em âmbito federal, a melhoria das condições higiênico-sanitárias dos alimentos preparados em padarias, cantinas, lanchonetes, bufês, confeitarias, restaurantes, comissárias, cozinhas industriais e institucionais ${ }^{3}$.

As denominadas Boas Práticas para serviços de alimentação contemplam ainda a manutenção e higienização das instalações, dos equipamentos e dos utensílios; o controle da água de abastecimento e de vetores transmissíveis de doenças e pragas urbanas; a capacitação profissional e a supervisão da higiene e da saúde dos manipuladores; o manejo correto de resíduos como o lixo; e o controle e a garantia de qualidade do alimento preparado.

Quanto à manipulação, responsáveis pelo preparo destes, as regras são bem claras. Esses funcionários não podem apresentar lesões ou sintomas de enfermidades que venham a comprometer a qualidade sanitária dos alimentos, devendo, quando nessas condições, ser afastados da atividade. Outras exigências: asseio pessoal, uniformes compatíveis e anti-sepsia periódica das mãos.

Outras regras básicas dizem respeito ao preparo dos alimentos, proibindo o contato direto do manipulador pela obri-

3 Revista de Direito do Consumidor (RDC) No. 216, de 15 de setembro de 2004. da Anvisa. gatoriedade do uso de toucas, luvas descartáveis, bem como às áreas de exposição do alimento preparado ao consumo, com a instalação de barreiras de proteção e isolamento da área de recebimento de dinheiro e outros meios utilizados para pagamento de despesas, com a vedação de que funcionários que exerçam esta função manipulem alimentos, mesmo que embalados.

Editada em setembro de 2004, a Resolução concedeu aos estabelecimentos comerciais, institucionais e industriais o prazo de 180 dias, a contar da data da publicação da resolução, para se adequarem a esse regulamento técnico. Os infratores estarão sujeitos a notificações e multas que variam de $R \$ 2$ mil a $R$ \$ 1,5 milhão, de acordo com a Lei No. 6.437/77.

Outro tema muito interessante e pertinente é o dos chamados alimentos transgênicos ou organismos geneticamente modificados (OGM) com menção à Lei de Biossegurança e suas repercussões.

No ensino de Física, por exemplo, há campos exploratórios para os professores da área, podendo-se citar os acidentes de consumo como aqueles decorrentes de explosões de garrafas de refrigerantes confeccionadas em vidro ou em material polietileno conhecidas por PETs ( poli-tereftalato de etileno, plástico da família do poliéster),. no ato da abertura e não tão raros assim, elucidando aos alunos suas causas físicas bem como as responsabilidades deles decorrentes e impostas aos proprietários de estabelecimentos comerciais e fabricantes. 
O Código de Defesa do Consumidor ocupa-se também pela proteção à saúde e segurança dos consumidores e um bem extremamente valioso é especialmente tutelado: a vida do consumidor e o fornecimento de produtos ou serviços que se afigurem perigosos ou nocivos à saúde ou que possam comprometer a segurança dos consumidores estará sujeitará o fornecedor a três tipos de sanções: civis, pelos danos decorrentes dos infortúnios, administrativos que abrangem a responsabilidade dos fornecedores diante dos órgãos federais, estaduais e municipais e penais correspondentes à prática de infrações penais pelos fornecedores.

Quanto às informações sobre potenciais perigosidades, o diploma legal dispõe no artigo $8^{\circ}$, que os produtos $\mathrm{e}$ serviços colocados no mercado de consumo não acarretarão riscos à saúde ou segurança dos consumidores, exceto os considerados normais e previsíveis em decorrência de sua natureza e fruição, obrigando-se os fornecedores, em qualquer hipótese, a dar as informações necessárias e adequadas a seu respeito. No Parágrafo único deste artigo há determinação para que, no caso de produtos industriais, cabe ao fabricante prestar as informações sobre o que se refere o artigo comentado.

Suas obrigações porém não cessam aí. $O$ artigo seguinte, $9^{\circ}$., dispõe que 0 fornecedor de produtos e serviços potencialmente nocivos e perigosos à saúde ou segurança deverá informar, de maneira ostensiva e adequada a respeito de sua nocividade ou periculosidade, sem prejuí- zo da adoção de outras medidas cabíveis em cada caso concreto. Podem ser considerados exemplos de produtos e serviços potencialmente perigosos ou nocivos, o comércio tabagista, de bebidas alcoólicas, defensivos agrícolas (agrotóxicos), produtos contendo materiais radioativos, dedetização e outros.

No que se refere ao comércio de álcool e cigarros, o tema envereda para a Saúde Pública - Educação para a Saúde - permitindo aludir à prevenção educacional primária, incluindo o tema da forte influência da mídia através da propaganda destes produtos, especialmente na guerra declarada entre os fabricantes de cervejas que avultam nas propagandas veiculadas na televisão.

Cabe também a discussão a respeito da questão das infecções hospitalares, sendo pertinente a recomendação para que as pessoas que forem utilizar um serviço de saúde verifiquem anteriormente a existência de comissões de controle da infecção hospitalar, extremamente importantes para promover garantias ao paciente, ainda que não seja possível se obter uma taxa de infecção zero, mas ensejando a prevenção de um grande número dessas infecções.

A Agência Nacional de Vigilância Sanitária (Anvisa), elaborou um sistema informatizado envolvendo Hospitais públicos e privados de todo o país para acompanhar a ocorrência e gravidade das infecções hospitalares.

O programa permite identificar indicadores de risco relacionados ao tempo 
de internação e de exposição a procedimentos invasivos, como as cirurgias, e as características dos pacientes e das unidades de internação.

De acordo com um levantamento encomendado pela Anvisa à Faculdade de Saúde Pública da Universidade de São Paulo (USP), dos 4.148 hospitais brasileiros avaliados entre 2001 e 2003, 72\% afirmaram que monitoram as infecções mas, por problemas metodológicos, os dados obtidos são confiáveis em apenas $13 \%$ deles.

$\mathrm{Na}$ área da matemática igualmente o campo de vinculação do Código de Defesa do Consumidor com a disciplina na prática diária é muito vasta.

Os cálculos de juros constituem um excelente exemplo. Os professores podem usar como tema o Sistema Financeiro da Habitação. É comum o fato de pessoas adquirirem imóveis por meio de financiamento, utilizando como sistema de amortização a tabela Price e no momento do pagamento da última parcela serem surpreendidos com um impagável saldo residual.

Poderá explicar os diversos sistemas de cálculo de juros e os malefícios da aplicação da tabela mencionada, demonstrando que num modelo econômico razoavelmente estável, sem troca de moedas, no qual não tenha ocorrido índices inflacionários, ao final do financiamento o mutuário irá pagar somente de juros o valor do capital emprestado, praticamente outro imóvel, isto em função da capitalização mensal dos juros.
Sob a ótica do CDC, o ponto a ser debatido, é discussão da utilização da tabela Price que contempla a contagem dos juros sobre juros, denominada anatocismo, que é veementemente proibida em nosso ordenamento jurídico e que gera um enorme desequilíbrio contratual entre as partes sempre com desvantagens financeiras ao mutuário.

Outras situações comuns de aquisição de bens (peças de vestuário, eletromésticos, automóveis etc.) mediante financiamento são também de interesse para a discussão com os alunos, mostrando o exorbitante acréscimo no valor em razão de juros, as características das propagandas na mídia, que estimulam o endividamento e distorcem o real balanço de perdas e ganhos, bem como o fato de que os contratos são geralmente apresentados como não sendo passíveis de negociação (ou se aceitam as regras pré-definidas ou a transação não é efetuada).

\section{Conclusão}

Como visto é amplo o campo de integração das diversas disciplinas da área de Ciências (Biologia, Física e mesmo a Química) e Matemática com as disposições deste notável instrumento protetivo do consumidor brasileiro.

Do ponto de vista social, o CDC que já completou 14 anos de vigência entre nós melhorou muito o relacionamento entre os consumidores e empresas.

Um exemplo disso é que os consumidores mostram-se cada vez mais informados sobre os seus direitos e muitas empresas 
intencionam um processo de transparência na esteira da criação dos chamados Serviços de Atendimento ao Consumidor (SAC).

Torna-se indispensável expandir o conhecimento desta norma, como ferramenta da cidadania e isto, sem dúvida pode configurar-se nas escolas, de maneira imbricada nos conteúdos disciplinares.

Se ainda há deficiências na lei, como afirmam alguns especialistas, tal fato pode ser aprimorado com a participação política das pessoas, papel para qual os alunos podem e devem, igualmente, ser preparados, até porque o $\mathrm{CDC}$ não eliminou totalmente a falta de respeito para com o público consumidor, ora por tolerância destes ou por decisões equivocadas da Justiça.

Portanto, diante especialmente dos ataques que o $\mathrm{CDC}$ tem freqüentemente sofrido por parte de segmentos econômicos, como os bancos, empresas de saúde privada e as agências de turismo, resistentes aos seus preceitos e lutando para que suas relações com os respectivos clientes não sejam reguladas por esta lei, é necessário e urgente que se passe a incentivar a educação para o consumo nas escolas.

\section{REFERÊNCIAS}

Agência Brasil - Agência de notícias do governo federal administrada pela Radiobrás, Dezembro 2004. Disponível em: www.radiobras.gov. br/sinopses.htm, em 20 de maio de 2005.

Brasil (1999). Parâmetros Curriculares Nacionais: Ensino Médio-Ciências da Natureza, Matemática e suas Tecnologias. V.3. Secretaria de Educação Fundamental. Brasília: MEC/SEF, 113 p.
Brasil. (2002). Secretaria de Educação Fundamental. Parâmetros Curriculares Nacionais Mais: Ensino Médio -Temas transversais. V.10. Brasília: MEC/SEF, 244 p. Disponível em: http://portal.mec.gov.br/seb/arquivos/ pdf/linguagens.pdf em 06 de novembro de 2005.

Brasil (2004). Revista de Direito do Consumidor (RDC) - Anvisa, No. 216, de 15 de setembro.

Driver, R.; Guesne, E., y Tiberghien, A. (1989). Las ideas de los niños y el aprendizaje de las ciencias, El proceso de combustión y "Conclusiones". Ideas científicas en la infancia y en la adolescencia. Madrid: MEC/ Morata, pp. 19-30, 240.

Filomeno, J. G. (1999). Manuel de Direitos do Consumidor. $3^{a}$ Ed. São Paulo: Atlas. 580 p.

Frers, C. (2005). La Problemática dela Educación Ambiental:disponível em: Ecoportal. net, Buenos Aires, Argentina, 22 de maio.

Grinover, A. P., et alii. (1999). Código Brasileiro de Defesa do Consumidor Comentado pelos autores do Projeto. $6^{\mathrm{a}}$ Ed. Rio de Janeir: Forense Universitária. 1012 p.

Morin, E. (2002). A cabeça bem feita. Repensar a reforma, reformar o pensamento. $7^{\mathrm{a}}$ Ed. Rio de Janeiro: Bertrand Brasil.

Sanmarti, N. (1999). Hablar y escribir : una condición necesaria para aprender ciencias. En: Cuadernos de pedagogía, No. 281, junio, pp.54-58.

Zabala, A. (2002). Enfoque globalizador e pensamento complexo. Uma proposta para o currículo escolar. Porto Alegre. 248 p.

ARTículo RECIBIDO: 15-05-2005 Y APROBADO: 11-11-2005 